\title{
Earthquake Induced Liquefaction Potential of Paste Tailings: Shaking Table Results
}

\author{
Fahad Alshawmar ${ }^{1,2}$, Mamadou Fall ${ }^{1}$ \\ ${ }^{1}$ Department of Civil Engineering, Faculty of Engineering, University of Ottawa \\ 161 Louis Pasteur, Ottawa, Ontario, Canada K1N 6N5 \\ ${ }^{2}$ Department of Civil Engineering, Faculty of Engineering, Qassim University \\ Buraydah, 51431 Al Qassim, Saudi Arabia \\ falsh073@uottawa.ca; mfall@uottawa.ca
}

\begin{abstract}
Highly densified tailings, such as paste tailings, are a novel technology of tailings (soils produced by mining activities) disposal and management. Paste tailings are generated from the significant dewatering of the slurry tailings produced in the mine processing plant. This technology provides numerous benefits to the mines, such as reduction of the dependency on conventional tailings dams with their associated risks (disastrous geotechnical and environmental failures) and the increase in water recovery and recycling. However, regulators are worried about liquefaction potential of paste tailings deposits in regions that are prone to earthquakes. Up to date, no investigations have been conducted to evaluate the liquefaction potential of paste tailings using a shaking table. Therefore, the purpose of this research is to evaluate the liquefaction potential of paste tailings under seismic loading conditions using one-dimensional shaking table equipment. The paste tailings were deposited in thin layers and were subjected to the atmospheric desiccation process in order to gain strength before performing the shaking table tests. The paste tailings deposit was subjected to a sinusoidal dynamic loading with a frequency of $1 \mathrm{~Hz}$ and peak horizontal acceleration of $0.13 \mathrm{~g}$. The variation of pore-water pressure within paste tailings deposit was monitored during the shaking test. The test results showed that the paste tailings can be susceptible to liquefaction under the considered testing conditions.
\end{abstract}

Keywords: Paste tailings, Liquefaction, Shaking table, Dynamic loading, Pore-water pressure

\section{Introduction}

The mining industry generates vast amounts of mine tailings every year worldwide. Worldwide, the amount of generated mine tailings from the mining industry was 14 billion tonnes in 2010 [1]. Typically, mine tailings can be defined as the finely ground waste that are left over after metal extraction from ores [2]. Tailings are deposited conventionally in form of slurry in the disposal area which retained via a structure known as tailings dams. Such conventional disposal form has been known to be facing key problems, specifically in terms of the failures of tailings dams that occurred due to liquefaction phenomena during an earthquake shaking. Normally, the slurry tailings deposits in the tailings dams are considered to be soft, loose and remained under saturated condition which thus they will be susceptible to seismic liquefaction under the occurrence of any significant earthquakes [3]. The disastrous failure of the Las Palmas tailings dams during the 2010 Maule, Chile Earthquake is considered one of the well-known recent examples of the seismic-induced liquefaction failure [4, 5]. Consequently, this disastrous caused the tailings to flow to an approximately $0.5 \mathrm{~km}$ as well as four people lost their lives.

Highly densified tailings, such as paste tailings, are a novel technology of tailings disposal and management that have been developed to reduce the dependency on conventional tailings dams with their associated risks (disastrous geotechnical and environmental failures) and to increase the water recovery and recycling. The term paste tailings technology can be defined as a dewatered slurry tailings that are not experience a critical flow velocity once pumped, are not subject to segregation after deposition and generate an insignificant amount of bleed water once discharged to the surface [6].This technology was firstly implemented as a surface disposal at the Bulyanhulu Gold Mine in Tanzania [6]. The solid content in the paste tailings is ranged between $70 \%$ and $85 \%$, with a yield stress ranging between 100 and $1000 \mathrm{~Pa}$ [7]. Generally, the flow of pate tailings will rest at slope that can range between $3^{\circ}$ and $10^{\circ}$ as long as the underlying material has stabilized [6].

Previous laboratory studies of the dynamic response of tailings have been performed mostly using conventional cyclic equipment, such as direct simple shear or triaxial equipment (e.g., $[8,9,10,11,12,13])$. Yet, to the best knowledge of the 
authors, very few laboratory studies $[14,15]$ that have been tested the dynamic response of conventional tailings (i.e., slurry tailings) using shaking table equipment. However, to-date, no investigations have been conducted to evaluate the liquefaction potential of paste tailings using a shaking table equipment. Liquefaction potential of paste tailings is considered a vital concern, specifically in regions that are prone to earthquakes. Therefore, the purpose of this research is to evaluate the seismic liquefaction potential of paste tailings under dynamic loading conditions by using onedimensional shaking table equipment. There is a need to address such concern in terms of the liquefaction potential of paste tailings.

\section{Materials and Methods}

\subsection{Materials}

The materials used in this investigation contain tailings and tap water. The tailings studied involve a mixture of silica tailings (STs) and natural tailings (NTs). This mixture of tailings was intended to minimize the impact of uncertainties on the testing results as the natural tailings (NTs) are often contain sulfide minerals while the silica tailings (STs) its chemical and mineralogical compositions can be controlled [16]. The silica tailings (STs), ground silica, are considered synthetic tailings and are essentially made of quartz, which is one of the predominant minerals in Canadian hard rock tailings [17]. The natural tailings (NTs) were brought from a mine located in the eastern part of Canada. The grain size distribution of the mixture (paste tailings) is close to that of the average of 9 Canadian mine tailings, as shown in Figure 1, [18, 19].

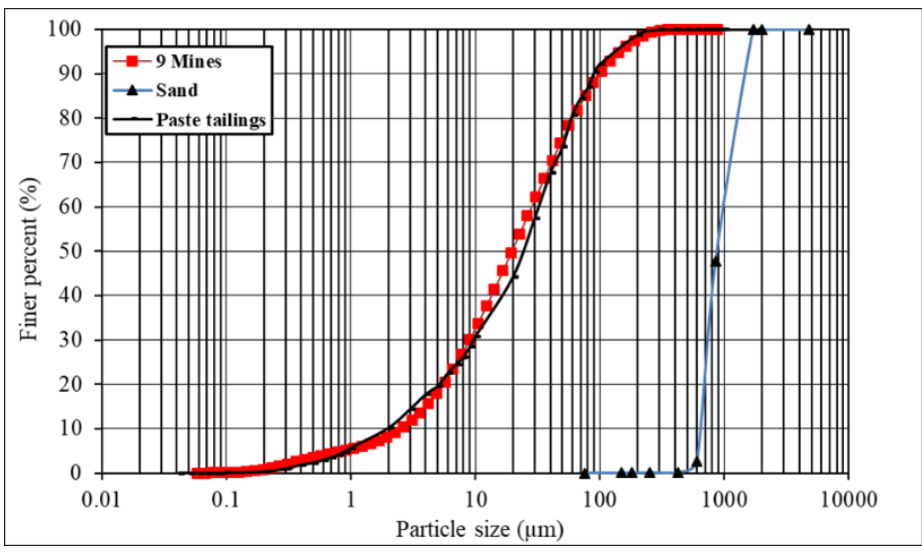

Fig. 1: Grain size distribution of the used paste tailings and sand in this research compared with the average of 9 Canadian mine tailings.

\subsection{Paste Tailings Preparation}

The paste tailings were prepared via adding tap water to the mixture of the silica tailings (STs) and natural tailings (NTs). The silica tailings (STs) and the natural tailings (NTs) represented a $90 \%$ and $10 \%$ of the tailings mixture, respectively. An electrical concrete mixer was used to mix the water and tailings thoroughly for a duration of approximately of $10 \mathrm{~min}$ in order to obtain homogeneity. The workability of the prepared paste tailings was evaluated through the yield stress test. It was found that the yield stress of the prepared tailings was approximately $139 \mathrm{~Pa}$. The yield stress was determined based on a single-point measurement (the maximum torque) [20]. This prepared tailing was then poured in thin layers into a flexible laminar shear box (FLSB), which described briefly below.

\subsection{Shaking Table}

In this investigation, the shaking table equipment of the University of Ottawa, Canada, was used in order to simulate the seismic behaviour of the paste tailings under the one-dimensional of shaking loading (Figure 2). 
This equipment has an aluminium platform $(\sim 1000 \times 1000 \mathrm{~mm}$ as a plan area) with a maximum capacity of $1000 \mathrm{~kg}$. The shaking table can be moved horizontally back and forth at different frequencies ranging from 1 to $17 \mathrm{~Hz}$ with a maximum displacement of $\pm 120 \mathrm{~mm}$ and a maximum base shear capacity of $25 \mathrm{kN}$ through a hydraulic actuator.

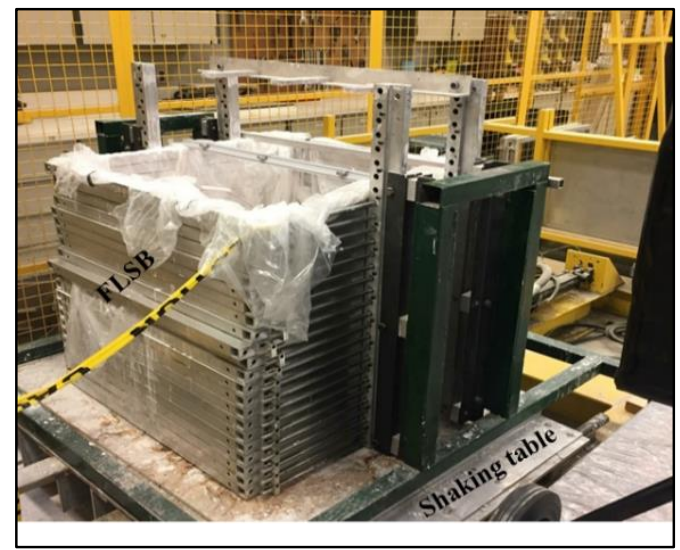

Fig. 2: Photo of the shaking table and flexible laminar shear box (FLSB) used in this research.

\subsection{Flexible Laminar Shear Box, Setup and Instrumentation}

Seismic response of the paste tailings was investigated through using a flexible laminar shear box (FLSB) that was mounted on the shaking table, as shown in Figure 2. The used FLSB was designed by [21] and constructed in the machine shop at the University of Ottawa, Ottawa, Canada. This FLSB has the dimensions of $750 \mathrm{~mm}$ in length, $750 \mathrm{~mm}$ in width, and $750 \mathrm{~mm}$ in height, where it was constructed via staking a set of 22 horizontal laminae on top of each other with a slight space $(2 \mathrm{~mm})$ between each of them to allow for the relative movement during the shaking test. These laminae were made up of aluminium material with dimensions of $31.65 \mathrm{~mm} \times 31.65 \mathrm{~mm}$.

A plastic sheet with thickness of approximately $0.5 \mathrm{~mm}$ was placed inside the FLSB to hold the prepared paste tailings deposit as well as the sand material. The grain size distribution of this used sand material can be shown in Figure 1. This sand material was poured into the FLSB, below the paste tailings deposit, to form a slope of approximately 5.6\%. This selected slope was within the ranged that reported for the paste tailings in the field [6]. A geotextile sheet was placed between the sand material and the prepared paste tailings deposit to work as a porous barrier between them. The prepared paste tailings were then deposited in three thin layers (i.e., each had a thickness of $150 \mathrm{~mm}$ ) into the FLSB subsequently to simulate the surface disposal of paste tailings at the Bulyanhulu gold mine, Tanzania [6], as shown in Figure 3. Deposition in thin layer is considered very important for strength gain through desiccation [6]. The duration between the deposition of the first layer (bottom layer) and the second layer (middle layer) was 3 days while it was 2 days between the second layer (middle layer) and the third layer (top layer).

Pore pressure transducers (Model PX309-015CG5V, Omega Company) were installed at the middle depth of each thin layer of the paste tailings deposit to measure the change in the pore water pressure during the applied shaking loading, as shown in Figure 3. These transducers were connected to a data acquisition system to record the data. 


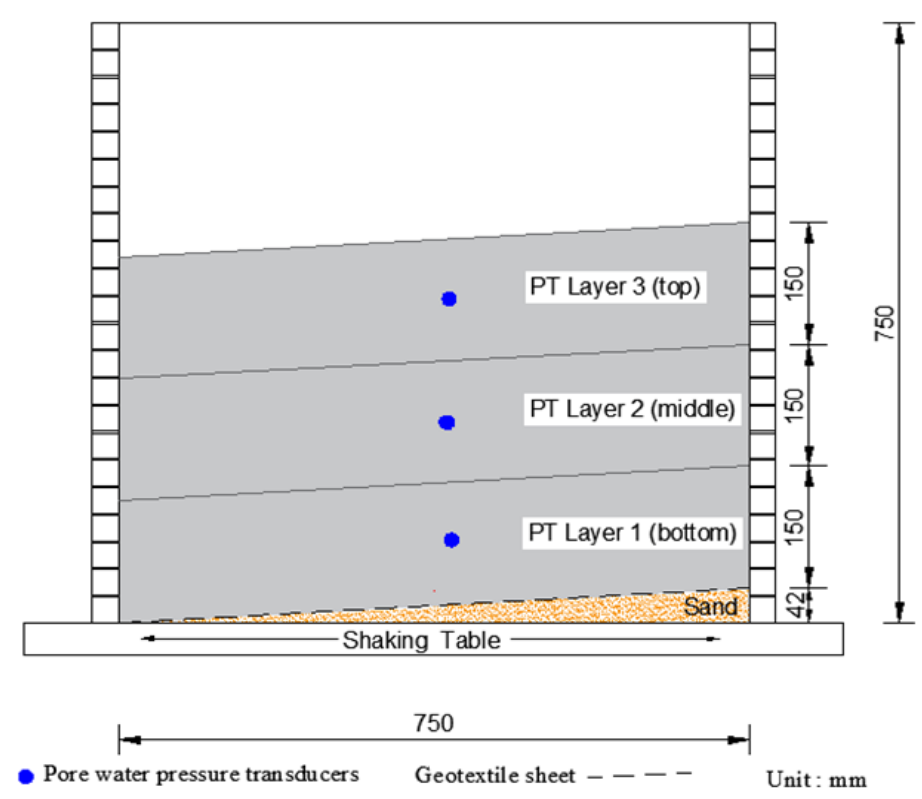

Fig. 3: Schematic drawing of the instrumented FLSB with layers of paste tailings mounted on the shaking table.

\subsection{Dynamic Testing}

The experimental testing in this investigation involved of using the shaking table to apply a sinusoidal dynamic loading with a frequency of $1 \mathrm{~Hz}$ and peak horizontal acceleration of $0.13 \mathrm{~g}$ at the bottom of the paste tailings deposit for a duration of 1,800 seconds. The designated loading frequency in this investigation was based on previous shaking table studies (e.g., $[22,23,14])$ and compatible with the ability of the used transduces in terms of the monitoring. In addition, the influence of the loading frequency was reported to be somewhat insignificant in laboratory testing [24, 25]. The designated peak horizontal acceleration in this investigation was similar to the acceleration of the Saguenay earthquake of 1988 in Québec, Canada, which had a magnitude of 5.9 [26]. The designated long duration of shaking loading in the current investigation was not intended to simulate the actual duration of earthquakes, which are known to be much shorter. Furthermore, a good observation of the dynamic response of the paste tailings deposit and relative comparisons of their response can be obtained via a long duration of shaking loading (e.g., 1,800 seconds). Accordingly, this is considered vital for the future development of a constitutive model to predict and evaluate the seismic response of paste tailings deposit. A previous seismic liquefaction study on hard rock tailings [14] has been used such a long duration of shaking loading. The paste tailings deposit was subjected to shaking loading 1 day after the deposition of the third layer (top layer) of paste tailings.

\section{Samples of Test Results and Discussions}

This section provides samples of the test results that associated with a key parameter that is known as the excess porewater pressure ratio, which has been used commonly to evaluate the liquefaction potential of soils and tailings during the applied dynamic loading. Previous seismic liquefaction studies (e.g., $[23,14,15]$ ) have been used this ratio as an indication of the liquefaction occurrence. The development of the excess pore-water pressure and its corresponding excess pore-water pressure ratio were presented herein only at the middle depth of the first layer (bottom layer) and the third layer (top layer) of the paste tailings deposit. The excess pore-water pressure ratio $\left(r_{u}\right)$ at the middle depth of these layers of the paste tailings can be determined, as shown in Eq. (1) below.

$$
r_{u}=\frac{\Delta u}{\sigma_{v o}^{\prime}}
$$


Where $\Delta u$ is the excess pore-water pressure during shaking and $\sigma_{v o}^{\prime}$ is the initial vertical effective stress before the shaking. The soils or tailings materials is considered under liquified condition when the $r_{u}$ equals 1 or is close to 1 [23, 14]. It has to be mentioned that other previous studies $[27,28]$ indicated that soils might be under liquefaction condition when the $r_{u}$ is within the range of 0.7 to 1.0 .

The time histories of the excess pore-water pressure measured at the middle depth of these layers of the tested past tailings and the corresponding excess pore-water pressure ratio are presented in terms of during shaking loading, as shown in Figures $4 \mathrm{a}$ and $4 \mathrm{~b}$. As it can be seen in Figure 4a, the excess pore-water pressure at the middle depth of these layers was observed to be developed quickly till reaching a peak value; then, it became slightly steady till the termination of the shaking loading. The volume contraction of the tested tailings is considered the primarily caused of such quick developed in the excess pore-water pressure at the beginning of the shaking loading. The observed relative steadiness of the excess pore-water pressure following the peak value can be associated with a volume dilative response of the tested paste tailings to loading at very low effective stress [14]. It was noticed that the bottom layer attained higher peak value of the excess pore-water pressure than that at the top layer. This higher value of excess pore-water pressure in the bottom layer can be resulted from the downward flow of pore-water from the upper layer to the bottom layer of the tested tailings. This pore-water pressure in the bottom layer is resulted partially via pore pressures produced in the bottom layer and partially via inflow of pore-water from the upper layer. In addition, this above-mentioned description can be supported by the findings of previous researchers [27], which they stated that earthquake shaking of layered soils induce pore water gradients, inflow of pore water in some areas or layers and outflow of pore water in some areas. Typically, at both the bottom and top layers of the paste tailings deposit, the excess pore-water pressure ratio was lower than unity $\left(r_{u}<1\right)$, ranging from approximately 0.7 to 0.9 during the shaking loading, as shown in Figure 4b.

When the shaking loading terminated, the excess pore-water pressure at both layers increased abruptly till reaching a maximum value, as shown in Figure 4a. Accordingly, the excess pore-water pressure ratios at the bottom and top layers of the tested paste tailings were approaching unity $\left(r_{u} \approx 1\right)$, as shown in Figure $4 \mathrm{~b}$, as a result of such abrupt increase in porewater pressure, which reveals that the highly densified tailings in terms of paste tailings could be susceptible to liquefaction under the considered testing conditions. Since there is a smaller vertical stress at the top layer, the top layer was observed to have a lower magnitude of this abrupt increase compared to the bottom layer. Such abrupt increase in excess pore-water pressure was resulted due to two mechanisms. First, the termination of the dynamic loading, which allowed the contraction of tailings particles that were partially in suspension, thus producing additional pore-water pressure [14]. Second, an upward flow of pore-water from the bottom part of the paste tailings deposit to the top layer (layer 3 ) and a downward flow of porewater from the bottom part of the middle layer of the paste tailings deposit to the bottom layer (layer 1) that produced additional pore-water pressure. Previous liquefaction studies $[14,15]$ on hard rock tailings reported similar findings.
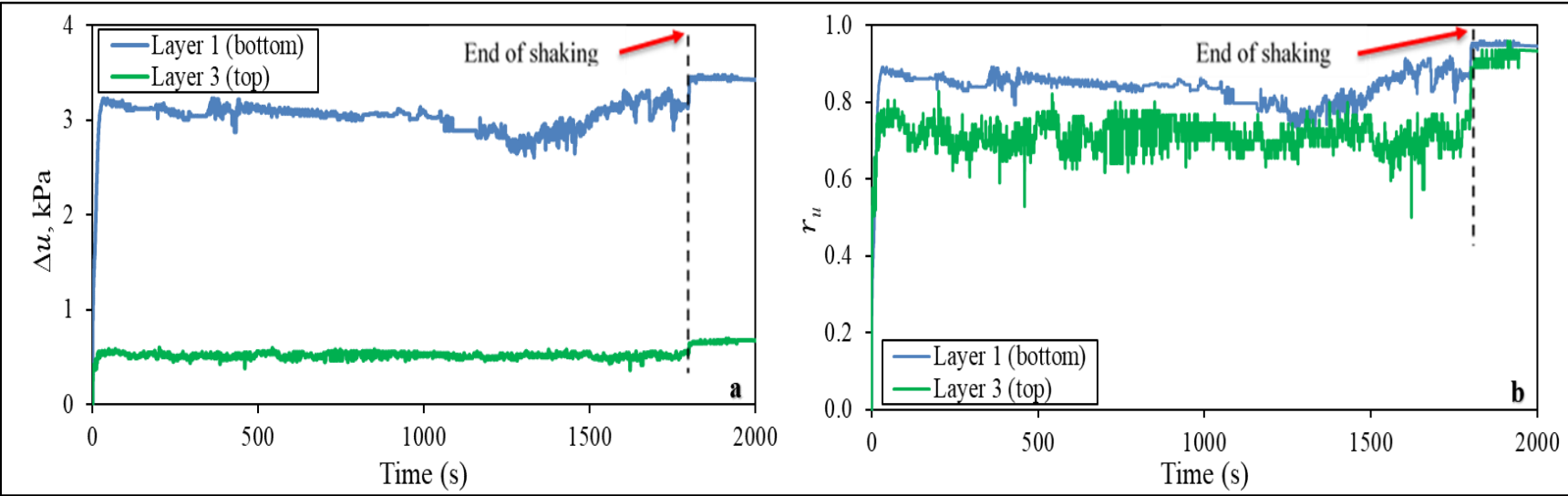

Fig.4: Time histories of excess pore-water pressures at the middle depth of bottom and top layers of paste tailings during shaking loading: (a) measured excess pore water pressure $(\Delta u)$ and (b) excess pore-water pressure ratio $\left(r_{u}\right)$. 


\section{Conclusion}

In this research paper, liquefaction potential of paste tailings deposit was evaluated using shaking table equipment. Based on the test results of this research paper, the following conclusions can be outlines as follows.

Both the bottom and top layers of paste tailings deposit were experienced volume contraction, which therefore led quick development in the excess pore-water pressure during shaking loading.

An abrupt increase of the excess pore-water pressure was noticed immediately, at both layers of paste tailings deposit, after the shaking loading was terminated. This caused to the excess pore-water pressure ratio of both layers of paste tailings deposit to approach unity. Such abrupt increase in the excess pore-water pressure was associated with both the volume contraction of paste tailings particles that were partially in suspension and the upward flow of pore-water to the top layer and downward flow of pore-water to the bottom layer.

Based on the above observations, the paste tailings deposit could be susceptible to liquefaction under the applied frequency of $1 \mathrm{~Hz}$ and peak horizontal acceleration of $0.13 \mathrm{~g}$. Therefore, the wariness must be taken in case of implementation of paste tailings technology in regions that located in high seismic activates.

\section{Acknowledgements}

The authors would like to acknowledge the Natural Sciences and Engineering Research Council of Canada (NSERC), Qassim University, Kingdom of Saudi Arabia, and University of Ottawa, Canada, for supporting this research.

\section{References}

[1] H. Jones and D. V. Boger, "Sustainability and waste management in the resource industries," Ind. Eng. Chem. Res., vol. 51, no. 30, pp. 10057-10065, 2012.

[2] B. Elbefling and V. Nicholson, "Field determination of sulphide oxidation rates in mine tailings," Water Resour. Res., vol. 32, no. 6, pp. 1773-1784, 1996.

[3] K. Ishihara, "Post-earthquake failure of a tailings dam due to liquefaction of the pond deposit," in Proceedings of the First International Conference on Case Histories in Geotechnical Engineering, St. Louis, MO, 1984, vol. 3, pp. 11291143.

[4] J. Bray and D. Frost. (2010, May 25). Geo-engineering reconnaissance of the 2010 Maule, Chile Earthquake (Ver2) [Online]. Available:

http://www.geerassociation.org/administrator/components/com_geer_reports/geerfiles/Maule_Chile_2010/Ver2_Maul e_Chile_2010_index.html

[5] R. Verdugo and J. González, "Liquefaction-induced ground damages during the 2010 Chile earthquake," Soil Dyn. Earthq. Eng., vol. 79, pp. 280-295, 2015.

[6] J. Theriault, J. Frostiak, and D. Welch, "Surface disposal of paste tailings at the Bulyanhulu gold mine, Tanzania," in Proceedings of Sudbury Mining and the Environment Conference, Sudbury, ON, 2003, pp. 1-8.

[7] B. Bussière, "Colloquium 2004: Hydrogeotechnical properties of hard rock tailings from metal mines and emerging geoenvironmental disposal approaches,” Can. Geotech. J., vol. 44, no. 9, pp. 1019-1052, 2007.

[8] J. Crowder, "Deposition, consolidation, and strength of a non-plastic tailings paste for surface disposal," Ph.D. dissertation, Dept. Civ. Eng., Univ. Toronto, Toronto, ON, 2004.

[9] D. Wijewickreme, M. V. Sanin, and G. R. Greenaway, "Cyclic shear response of fine-grained mine tailings," Can. Geotech. J., vol. 42, no. 5, pp. 1408-1421, 2005.

[10] M. James, M. Aubertin, D. Wijewickreme, and G. W. Wilson, "A laboratory investigation of the dynamic properties of tailings," Can. Geotech. J., vol. 48, no. 11, pp. 1587-1600, 2011.

[11] A. M. Geremew and E. K. Yanful, "Dynamic properties and influence of clay mineralogy types on the cyclic strength of mine tailings," Int. J. Geomech., vol. 13, no. 4, pp. 441-453, 2013.

[12] F. Daliri, H. Kim, P. Simms, and S. Sivathayalan, "Impact of desiccation on monotonic and cyclic shear strength of thickened gold tailings," J. Geotech. Geoenvironmental Eng., vol. 140, no. 9, p. 04014048, 2014.

[13] L. Hu, H. Wu, L. Zhang, P. Zhang, and Q. Wen, "Geotechnical properties of mine tailings,” J. Mater. Civ. Eng., vol. 
29, no. 2, p. 04016220, 2017.

[14] N. Pépin, M. Aubertin, and M. James, "Seismic table investigation of the effect of inclusions on the cyclic behaviour of tailings," Can. Geotech. J., vol. 49, no. 4, pp. 416-426, 2012a.

[15] N. Pépin, M. Aubertin, M. James, and M. Leclerc, "Seismic simulator testing to investigate the cyclic behavior of tailings in an instrumented rigid box," Geotech. Test. J., vol. 35, no. 3, pp. 469-479, 2012b.

[16] L. Cui and M. Fall, "Mechanical and thermal properties of cemented tailings materials at early ages: Influence of initial temperature, curing stress and drainage conditions," Constr. Build. Mater., vol. 125, pp. 553-563, 2016.

[17] M. Fall and O. Nasir, "Mechanical behaviour of the interface between cemented tailings backfill and retaining structures under shear loads," Geotech. Geol. Eng., vol. 28, no. 6, pp. 779-790, 2010.

[18] L. Orejarena and M. Fall, "Mechanical response of a mine composite material to extreme heat," Bull. Eng. Geol. Environ., vol. 67, no. 3, pp. 387-396, 2008.

[19] M. Pokharel and M. Fall, "Combined influence of sulphate and temperature on the saturated hydraulic conductivity of hardened cemented paste backfill," Cem. Concr. Compos., vol. 38, pp. 21-28, 2013.

[20] N. Q. Dzuy and D. V. Boger, "Direct Yield Stress Measurement with the Vane Method," J. Rheol., vol. 29, no. 3, pp. 335-347, 1985.

[21] I. Alainachi and M. Fall, "Seismic induced liquefaction of cemented paste backfill: effect of mixing water," in Proceedings of the 7th International Conference on Earthquake Geotechnical Engineering, Rome, Italy, 2019, pp. 10421049.

[22] M. James, D. Jolette, M. Aubertin, and B. Bussière, "An experimental set-up to investigate tailings liquefaction and control measures," in Proceedings of the International Symposium on Major Challenges in Tailings Dams (ICOLD), Montreal, Que., 2003, pp. 153-164.

[23] T. S. Ueng, C. W. Wu, H. W. Cheng, and C. H. Chen, "Settlements of saturated clean sand deposits in shaking table tests," Soil Dyn. Earthq. Eng., vol. 30, no. 1-2, pp. 50-60, 2010.

[24] K. Ishihara, Soil behaviour in earthquake geotechnics. Oxford, UK: Clarendon Press, 1996.

[25] S. Sriskandakumar, "Cyclic loading response of Fraser River sand for validation of numerical models simulating centrifuge tests," Ph.D. dissertation, Dept. Civ. Eng., Univ. British Columbia, Vancouver, BC, 2004.

[26] M. Tuttle, K. T. Law, L. Seeber, and K Jacob, "Liquefaction and ground failure induced by the 1988 Saguenay, Quebec, earthquake,” Can. Geotech. J., vol. 27, no. 5, pp. 580-589, 1990.

[27] E. Naesgaard and P. M. Byrne, "Flow liquefaction simulation using a combined effective stress-total stress model," in Proceedings of the 60th Canadian Geotechnical Conference, Ottawa, ON, 2007, pp. 1-8.

[28] D. C. Serafini and V. Perlea, "Comparison of liquefaction triggering analysis approaches for an embankment dam and foundation," in Proceedings of the 5th International Conference on Recent Advances in Geotechnical Earthquake Engineering and Soil Dynamics, San Diego, California, 2010, pp. 1-11. 